\title{
INDICAÇÃO GEOGRÁFICA COMO INSTRUMENTO DE ORIENTAÇÃO PARA O MERCADO: UM ESTUDO NAS VINÍCOLAS PRODUTORAS DE VINHOS FINOS NO VALE DOS VINHEDOS-RS
}

DOI: http://dx.doi.org/10.18616/pidi07

Paloma de Mattos Fagundes - UFSM

E-mail:palomattos@hotmail.com Ana Claudia Machado Padilha - UPF E-mail: anapadilha@upf.br Anelise Daniela Schinaider - UFRGS E-mail: aneliseschinaider@gmail.com Alessandra Daiana Schinaider - UFRGS 


\section{INTRODUÇÃO}

A demanda dos países em desenvolvimento tem dado um novo direcionamento ao ciclo de vida dos produtos agrícolas. Esse incremento, no entanto, não eliminou a importância da diferenciação e da segmentação dos mercados agroalimentares. Pelo contrário, o rápido crescimento econômico e urbano amplia também a perspectiva de crescimento de mercados para produtos diferenciados com valor agregado.

O Brasil se destaca na produção e na exportação de carne bovina, frango, açúcar, café, soja, milho e outras commodities. Nesse sentido, ressalta-se que grandes empresas do agronegócio brasileiro vêm agregando valor aos seus produtos e avançando em mercados externos com investimentos diretos em setores como o de bebidas, de carnes e de açúcar/álcool (WILKINSON, 2010). Assim, como estratégia para ampliar a capacidade das organizações na obtenção de competitividade, torna-se relevante aprofundar estudos que abordem a orientação para o mercado como instrumento de criação de valor para o cliente no âmbito das empresas do agronegócio.

Empresas orientadas para o mercado devem ser capazes de responder rapidamente às demandas presentes e futuras do mercado, seja interno e/ou externo, como forma de estarem sempre à frente dos concorrentes. Além disso, a orientação para o mercado pode ser considerada um dos principais requisitos de criação de valor superior em mercados potenciais, gerando vantagem competitiva (SIMPSON et al., 2001; GRUNERT et al., 2005, 2010).

Estudos desenvolvidos por Kohli e Jaworski (1990), Narver e Slater (1990), Day (1994), Deshpandé et al. (1993) conceituaram e definiram a medição de constructos relacionados à orientação para o mercado, bem como comprovaram que quando ela é adotada por uma organização, permite uma performance superior nos negócios.

Dessa forma, na busca de entender como se dá a orientação para o mercado no âmbito dos agronegócios, valeu-se do paradigma SCP (Structure - Conduct - Performance), desenvolvido por Mason (1939) e Bain (1968), que, inseridos na Teoria da Economia Industrial, procuram explicar como as forças do mercado atuam sobre a conduta e a performance econômica das empresas.

Sendo assim, o conceito de orientação para o mercado, relacionado com o paradigma SCP, será analisado no contexto da Indicação Geográfica (IG) 
nas vinícolas produtoras de vinhos finos do estado do Rio Grande do Sul. Para melhor compreensão da IG, há a necessidade da dispersão de seus conceitos básicos que, como instrumento de orientação para o mercado, representa uma nova oportunidade a ser explorada, acrescentando um diferencial competitivo importante para as vinícolas que produzem vinhos finos e regionalizados, que podem ser difundidos para os mercados interno e externo.

O estado do Rio Grande do Sul possui a maior área de produção de uvas e é responsável por $90 \%$ da produção brasileira de vinhos (FLORES, 2012). Na Serra Gaúcha, a região conhecida como Vale dos Vinhedos merece destaque no que se refere aos vinhos finos produzidos com alta tecnologia. Essa região tem sido reconhecida, nacional e internacionalmente, como produtora de vinhos de qualidade. Uma evidência disso foi a criação da Indicação de Procedência Vale dos Vinhedos, em 2002, que motivou outros grupos de produtores da região a seguirem o mesmo caminho, ganhando competitividade em outros mercados, agregando valor, diferenciando os seus produtos e, principalmente, incrementando a performance econômica. O mesmo também ocorreu na Serra Geral e no Planalto dos Campos Gerais com a Indicação de Procedência Pinto Bandeira, em 2010; em Flores da Cunha e Nova Pádua com a Indicação de Procedência Altos Montes, em 2012; em Monte Belo, Bento Gonçalves e Santa Tereza com a Indicação de Procedência Monte Belo, em 2013; e em Farroupilha com a Indicação de Procedência Farroupilha, em 2015 (INPI, 2017a).

Como as questões de exportação para o produtor de vinho fino são desafiadoras, bem como a crescente exigência do consumidor interno por produtos de qualidade, elas promovem a necessidade de adoção de instrumentos inovadores que possam abrir as portas das organizações em diferentes mercados. Nessa realidade, a orientação para o mercado torna-se um pré-requisito para o sucesso e a lucratividade de muitas empresas, na busca pela competitividade e reconhecimento mundial.

Nesse sentido, tendo em vista a importância e a potencialidade da vinicultura no estado do Rio Grande do Sul, considera-se relevante a realização de estudos que permitam conhecer a performance econômica das vinícolas do setor de vinhos finos, a fim de contribuir para o aumento da competitividade das empresas participantes da cadeia produtiva do vinho diante das exigências dos mercados interno e externo. Assim, pretende-se analisar a performance econômica, a partir da IG, como instrumento de orientação de mercado das vinícolas produtoras de vinhos finos no Vale dos Vinhedos. 
Vale salientar que as abordagens, orientação para o mercado, SCP e IG serão utilizadas visando a um fim maior que é a geração de valor para os produtos e também para os stakeholders. Dessa maneira, caso a performance econômica da organização não fosse impactada pela adoção das práticas de orientação para o mercado, dificilmente seriam feitos investimentos evidenciando a pertinência de se estudar as suas relações. Assim, esta pesquisa pode contribuir para o desenvolvimento do campo acadêmico nessa área, colaborando no preenchimento da lacuna existente em conhecimentos que relacionem essas três abordagens.

\section{ORIENTAÇÃO PARA O MERCADO}

O termo "orientação para o mercado" surgiu em 1963, na Harvard Business Review, quando foi publicado o artigo "No easy road to market orientation", de autoria de Robert W. Lear, já indicando a preocupação existente com a orientação para o mercado (LEAR, 1963). Dois anos após a publicação do primeiro artigo que deu origem ao termo, Hugh L. Moore e Gorham Hussey, em 1965, publicaram, no Journal of Farm Economics, dois artigos sobre a orientação para o mercado na área de produção agrícola (MOORE; HUSSEY, 1965). Os autores analisaram as implicações econômicas da orientação para o mercado, ressaltando a necessidade de haver mudanças para melhor servir aos clientes: inovação e recursos alternativos. Essa condição demonstra a preocupação com a orientação para o mercado, principalmente em setores diferentes da indústria e do serviço. Mas foi a partir de 1990 que se desenvolveram diversos estudos que contribuíram para consolidar conceitos sobre orientação para o mercado, com destaque para os trabalhos de Kohli e Jaworski (1990), Narver e Slater (1990), Deshpandé et al. (1993) e Day (1994).

O constructo de Kohli e Jaworski (1990) trata da orientação para o mercado como um processo de geração e disseminação de inteligência de mercado e a capacidade de resposta da empresa. A inteligência de mercado envolve a análise dos fatores que podem influenciar as necessidades dos consumidores; a sua geração corresponde à busca de conhecimento sobre o mercado e à sua influência sobre o comportamento dos clientes. Uma vez gerada, a inteligência deve ser difundida por toda a organização, sendo transformada em ações concretas, voltadas à satisfação das necessidades e expectativas dos consumidores. 
Narver e Slater (1990) pesquisaram 371 executivos de uma organização americana e concluíram que a orientação para o mercado, como uma cultura organizacional, visa criar valor superior aos clientes e performance econômica superior para a organização a partir da união de três elementos comportamentais: orientação para o cliente, orientação para o concorrente e coordenação interfuncional. Esses elementos estão em estreita harmonia com as decisões relativas à visão de longo prazo e lucratividade da empresa. A orientação para o cliente é a capacidade de criar valor para os consumidores de forma constante e na dispersão dessas informações por toda a organização. Orientação para o concorrente consiste no conhecimento de suas forças e fraquezas de curto prazo, bem como das competências e estratégias de longo prazo de concorrentes atuais e potenciais. A interfuncional une todos os esforços da empresa, não apenas do marketing, em busca da criação de um valor superior para os clientes-alvo. Os autores também encontraram diferenças significativas entre empresas produtoras e não produtoras de commodities.

Deshpandé et al. (1993) analisaram a orientação para o mercado como um conjunto de crenças cujo primeiro plano está centrado nos interesses dos consumidores, mas não exclui outros envolvidos, como acionistas, funcionários, entre outros. Os autores expõem a natureza da orientação para o mercado sob um prisma cultural. Desse modo, definem a orientação para o mercado como um conjunto de atividades relacionadas à satisfação das necessidades dos clientes.

Na perspectiva de Day (1994), a empresa deveria exercer as suas atividades de forma superior a dos concorrentes, assim ela desenvolveria capacidades especiais. Uma organização orientada ao mercado possui as capacidades superiores de senso de mercado e ligação com o consumidor.

Para melhor entendimento, o Quadro 1 sintetiza as ideias centrais dos conceitos relacionados à orientação para o mercado, de acordo com os autores analisados. 
Quadro 1 - Resumo das ideias conceituais de orientação para o mercado

\begin{tabular}{|l|c|l|}
\hline \multicolumn{1}{|c|}{ Autores } & Ano & \multicolumn{1}{c|}{ Ideia Conceitual } \\
\hline Kohli e Jaworski & 1990 & $\begin{array}{l}\text { - Construção e utilização da informação; } \\
\text { - Inteligência de mercado. }\end{array}$ \\
\hline Narver e Slater & 1990 & $\begin{array}{l}\text { - Cultura organizacional; } \\
\text { - Criação de valor; } \\
\text { - Lucratividade; } \\
\text { - Performance superior contínua. }\end{array}$ \\
\hline Deshpandé et al. & 1993 & $\begin{array}{l}\text { - Prioridade no atendimento das necessidades dos clientes; } \\
\text { - Não considera uma cultura organizacional. }\end{array}$ \\
\hline Day & 1994 & $\begin{array}{l}\text { - Capacidades superior à dos concorrentes; } \\
\text { - Capacidades de prever as tendências do mercado; } \\
\text { - Capacidades difíceis de serem imitadas e desenvolvidas pela } \\
\text { concorrência. }\end{array}$ \\
\hline
\end{tabular}

Fonte: Elaborado com base em Kohli e Jaworski (1990), Narver e Slater (1990), Deshpandé et al. (1993) e Day (1994).

Nos estudos relacionados à orientação para o mercado, Pelham e Wilson (1996) reconhecem a natureza multidimensional da performance econômica e a importância de múltiplas medidas dessas dimensões. Entretanto Jaworski e Kohli (1993) basearam seu estudo na performance global, e Narver e Slater (1990) na lucratividade (retorno sobre ativos), no crescimento de vendas e no sucesso de novos produtos (PELHAM; WILSON, 1996).

Narver e Slater (1990) exploraram mais detalhadamente a utilização da lucratividade, do crescimento de vendas e sucesso de novos produtos como pré-requisito para uma performance econômica superior pelas organizações. Os autores foram pioneiros ao abordarem essas condições sobre o nível de orientação para o mercado. Para eles, as organizações, orientadas para o mercado, devem manter o foco igualmente no aumento do lucro, no crescimento das vendas e no sucesso de novos produtos, já que esses são os objetivos das organizações que buscam alcançar a competitividade e o diferencial diante da concorrência acirrada entre mercados. Já nas organizações sem fins lucrativos, deve-se manter o foco na sobrevivência em longo prazo.

Outros estudos (Kirca, Jayachandran e Bearden, 2005; Verhees e Meulenberg, 2004; Subramanian, Kumar e Strandholm, 2009; Nwokah, 2008; Jaworski e Kohli, 1993; Narver e Slater, 1990; Han, Kim e Srivastava, 1998; Wang et al., 2009) demonstram uma correlação positiva entre a orientação para o mercado e a performance econômica.

Para Micheels e Gow (2010), quando uma empresa descobre a necessidade de seus consumidores, ela transforma esse conhecimento em novos 
produtos, e o desempenho melhora a receita devido ao aumento dos preços e/ ou o aumento nas vendas. Para qualquer produto, seja commodity ou não, um aumento nos preços pode ser obtido pelos atores que se encontram a jusante, com um produto com atributos que eles valorizam.

O entendimento das relações entre os constructos de orientação para o mercado e o agronegócio permitirá que sejam desenvolvidas ações de forma a maximizar a imagem dos produtos com características regionais, difundidos no mercado interno, expandindo-a no mercado externo e determinando, assim, um aumento da performance econômica das empresas. Nesse sentido, para o estudo da performance econômica nas empresas, utiliza-se como base o modelo teórico SCP (Structure Conduct Performance), que tem como princípio básico a performance como reflexo das suas práticas competitivas ou padrões de conduta.

\section{MODELO TEÓRICO SCP (STRUCTURE CONDUCT PERFORMANCE)}

A literatura econômica oferece uma série de modelos que visam explicar o comportamento das empresas. Um dos modelos que se destacaram dentro da Organização Industrial é o SCP Paradigm (Struture - Conduct Performance), proposto por Mason (1939) e Bain (1968).

Na tradução, o Modelo Estrutura-Conduta-Desempenho tem como principal vantagem incluir os elementos-chave que definem a avaliação da vantagem competitiva, incorporando, segundo Fergunson e Fergunson (1994), relacionamentos causais entre a estrutura do mercado, a conduta das empresas e o seu desempenho econômico. Para Scherer e Ross (1990), a concepção do modelo tem como princípio básico que o desempenho de uma empresa é o reflexo de suas práticas competitivas ou padrões de conduta que, por sua vez, dependem da estrutura de mercado onde a empresa está inserida.

Em sua versão original, o modelo SCP visa analisar a lucratividade dos oligopólios, com o objetivo de implementar políticas antitruste, levando em consideração determinados aspectos. Utilizando premissas básicas, autores como Porter e Kramer (2005), Scherer e Ross (1990), McWilliams e Smart (1993) 
reconheceram a importância do modelo para a formulação do gerenciamento estratégico e a avaliação da performance econômica empresarial.

A estrutura do mercado é determinada pelo número de compradores e vendedores, pela diferenciação de produtos e estrutura de custos, pela integração vertical e diversificação e pela existência ou não de barreiras à entrada de concorrentes. Já a conduta das empresas preocupa-se com a determinação de preços, centrada, nesse caso, na definição de estratégias de produto e propaganda, programas de investimento, táticas legais (por exemplo, patentes) e P\&D. A performance econômica caracteriza-se pelo grau de eficiência alocada e produtiva, pelo processo técnico e, ainda, pelo nível de emprego e produtividade (SCHERER, 1996).

McWilliams e Smart (1993) estudaram, de forma comparativa, o modelo SCP e o paradigma de "eficiência", proposto pelos autores, destacando a falta de dinamismo nas análises com base no primeiro. Tung, Lin e Wang (2010) desenvolveram um modelo com base no SCP para analisar a quota de mercado, a publicidade e a rentabilidade na indústria internacional de hotéis turísticos. No agronegócio, alguns autores utilizaram o modelo SCP como instrumento de análise e avaliação dos mercados e da performance econômica (VIAENE; GELLYNCK, 1995; VAN DER WURFF, 2003; HARRE; PIRSCHER, 2009; CADILHON et al. 2009).

No período em que o modelo SCP foi desenvolvido, as limitações eram associadas à aceitação de hipóteses, dominantes no âmbito da teoria econômica, tornando-o mais favorável ao cenário econômico atual e sendo necessário adicionar novos elementos. Sendo assim, autores como Scherer e Roos (1990), bem como Fergunson e Fergunson (1994), incorporaram ao modelo tradicional fluxos entre os ambientes de estrutura, conduta e desempenho, pois admitem que a conduta das empresas e o seu desempenho são simultaneamente determinados e podem influenciar a estrutura de mercado.

Essa abordagem atribui maior abrangência ao modelo, tornando-o mais adequado para a análise de assuntos referentes à competitividade e à identificação de elementos, visando à orientação para o mercado. De fato, o modelo SCP continua sendo um referencial para análise da competitividade de empresas e indústrias, uma vez que considera os elementos-chave do ambiente em que as empresas operam; além disso, sua estrutura permite o aperfeiçoamento por meio da inclusão dos avanços recentes da teoria econômica.

Destaca-se que o paradigma SCP é o principal instrumento de intervenção sobre os mercados, apesar de várias críticas, como sobre seu caráter 
estático e a ausência de uma teoria consolidada. Dessa forma, o modelo SCP pode contribuir para as organizações voltadas ao agronegócio, por meio do desenvolvimento de práticas de orientação para o mercado, com o objetivo de influenciar positivamente a performance econômica, como é o caso da IG, a qual é um diferencial competitivo em mercados mais exigentes.

\section{INDICAÇÃO GEOGRÁFICA}

A origem do conceito de Indicação Geográfica surgiu quando produtores, comerciantes e consumidores perceberam que alguns produtos de determinadas regiões apresentavam qualidade superior em relação à sua origem geográfica (ADDOR; GRAZIOLI, 2002). A IG é uma forma de agregar valor e credibilidade a um produto ou serviço, conferindo-lhe um diferencial de mercado em função das características de seu local de origem.

No continente europeu, onde surgiram os primeiros indícios de nomes geográficos de procedência, em 1970, os produtores de vinho indicavam o produto pelo nome da região de sua produção, em função da dependência entre as características do vinho e fatores como o solo, o clima e o modo de fazer do produto. Um exemplo foram os produtores das regiões de Bourgogne e Bordeaux, na França, onde os vinhos provenientes daquelas regiões seriam classificados de acordo com os respectivos lugares de origem (BADCOCK; CLEMENS, 2004).

Moschini, Menapace e Pick (2008) ressaltam que o conceito de Terroir nasceu a partir da instituição de normas para a regulamentação dessas IGs, que traziam associadas características relativas ao solo, ao clima e a recursos humanos. Porém o aumento da demanda por esses produtos e o seu preço superior facilitou a utilização do nome geográfico em produtos que não tinham a mesma origem de procedência. Assim, aos poucos, foram surgindo normas específicas para regular a produção de produtos de origem geográfica e controlar o movimento de mercadorias, objetivando dar maior garantia à sua origem.

Alguns exemplos envolvendo produtos de notável qualidade, certificados e identificados com IGs podem ser citados: o champagne, vinho espumante procedente daquela região francesa; os vinhos tintos da região de Bordeaux; o presunto de Parma; o queijo Roquefort; e os charutos cubanos (TREJO-PECH et al., 2010). 
A Indicação Geográfica está ligada ao direito de propriedade intelectual e assegurada por várias convenções internacionais. A Organização Mundial da Propriedade Intelectual - OMPI e a Organização Mundial do Comércio - OMC são responsáveis pela aplicação de diversos tratados e convenções em nível internacional que tratam da IG (O'BRIEN, 1998).

Dentre os principais acordos relacionados à propriedade intelectual e às IGs estão: 1883 - Convenção de Paris; 1891 - Acordo de Madrid; 1924-1992 - Office International de la Vigne et du Vin - OIV; 1958 - Acordo de Lisboa; 1970 - Regras da União Europeia para os vinhos; 1992 - União Europeia para outros produtos; 1992 - NAFTA; 1993 - Acordo de Cartagena; 1994 - Acordo Trips; 1996 - Acordo do MERCOSUL (SILVA, 2010; JOSLING, 2006; TEIXEIRA, 2006).

No Brasil, o Decreto Federal no 1.355, de 30 de dezembro de 1994, em seu art. 22.1, define IG como

[...] as indicações que identifiquem um produto como originário do território de um membro, ou região ou localidade deste território, quando determinada qualidade, reputação ou outra característica do produto que seja essencialmente atribuída à sua origem geográfica. (BRASIL, 1994, n.p.).

Os produtos que apresentam uma qualidade única, explorando as características naturais, tais como geográficas (solo, vegetação), meteorológicas (mesoclima) e humanas (capacitação, zelo, capricho e conhecimento tácito aplicados no cultivo, tratamentos culturais), e que indicam de onde são provenientes, são aqueles que possuem um certificado de qualidade, atestando sua origem e garantindo o controle rígido de sua qualidade, denominado "indicação geográfica", nas modalidades de "indicação de procedência" ou "denominação de origem".

A Lei da Propriedade Industrial no 9.279, de 14 de maio de 1996, regulamenta as indicações geográficas em seus artigos no 176 a 183. Pelo art. no 177 da LPI,

[...] considera-se indicação de procedência o nome geográfico de país, cidade, região ou localidade de seu território, que se tenha tornado conhecido como centro de extração, produção ou fabricação de determinado produto ou de prestação de determinado serviço. (BRASIL, 1996, n.p.). 
No art. no 187, a denominação de origem é caracterizada como o nome geográfico de país, cidade, região ou localidade de seu território, que designe produto ou serviço, cujas qualidades ou características se devam exclusiva ou essencialmente ao meio geográfico, incluídos fatores naturais e humanos (BRASIL, 1996).

No Brasil, o Instituto Nacional de Propriedade Industrial (INPI) é a autarquia federal responsável pelos registros de IG. Desde 1997 até agosto de 2016, a Instituição recebeu 108 solicitações de registros, sendo 83 brasileiras, e reconheceu 41 regiões, dentre elas o vinho do Vale dos Vinhedos (RS); a carne do Pampa Gaúcho da Campanha Meridional (RS); o café da Região do Cerrado Mineiro (MG); a cachaça Artesanal de Paraty (RJ); a manga e a uva de mesa do Vale do Submédio São Francisco (BA/PE); o couro acabado do Vale dos Sinos (RS); o vinho tinto, branco e espumante de Pinto Bandeira (RS); o açafrão de Mara Rosa, Amaralina, Formoso e Estrela do Norte (GO); e o inhame da Região de São Bento de Urânia (ES).

No agronegócio brasileiro, as organizações envolvidas estão percebendo a necessidade de agregar valor aos seus produtos e de diferenciá-los perante o mercado competitivo, um exemplo disso são as solicitações de IGs no INPI (Figura 1).

Figura 1 - Solicitações de Registros para Indicação Geográfica

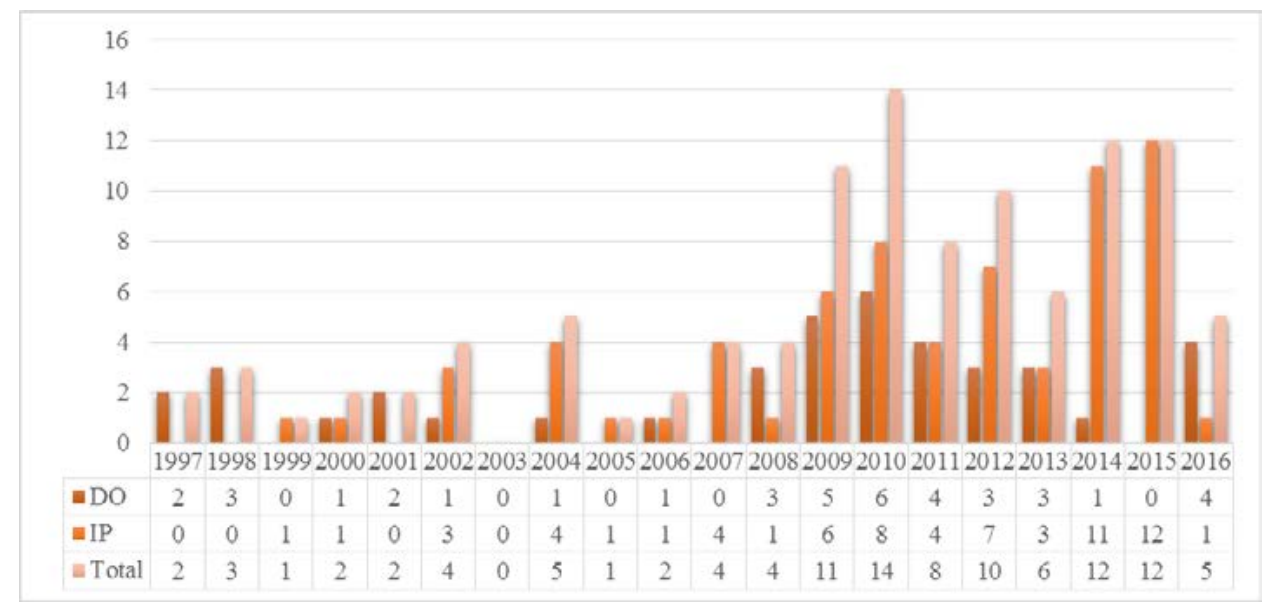

Fonte: INPI (2017b). 
A Figura 1 mostra essa percepção de mercado, com base nas solicitações de registros de IGs nos últimos anos. Apesar de o Brasil possuir doze solicitações de Denominação de Origem, até o momento, nenhuma foi reconhecida. Embora os temas estudados neste capítulo não sejam recentes, a orientação para o mercado, o paradigma SCP e a indicação de procedência ainda não haviam sido confrontados.

\section{METODOLOGIA}

O estudo é de natureza exploratória e qualitativa e tem como características metodológicas o uso de referências para a discussão dos temas propostos, bem como dados secundários que forneceram elementos para alcançar o objetivo proposto da pesquisa. Vale ressaltar que esta temática foi analisada à luz das abordagens de orientação para o mercado e do paradigma SCP.

Para auxiliar nesta análise, valeu-se da abordagem de orientação para o mercado, nas pesquisas de Kohli e Jaworski (1990) e Narver e Slater (1990), baseados em estudos sobre medida simples de performance global e de lucratividade (retorno sobre ativos), crescimento de vendas e sucesso de novos produtos de orientação para o mercado; e, também, do paradigmaSCP, que procura explicar como as forças do mercado atuam sobre a conduta e a performance das empresas.

É nesse entendimento que se percebe, na orientação para o mercado e no paradigma SCP, uma oportunidade de utilização, o que parece fazer sentido ao se buscar relacionar a IG como instrumento de dinâmica dos mercados, a fim de aumentar a performance econômica das organizações do agronegócio. A orientação para o mercado, o paradigma SCP e a indicação geográfica parecem ser uma resposta adequada para apresentar as vantagens apresentadas pelo setor de produção de vinhos finos após o reconhecimento da Indicação de Procedência Vale dos Vinhedos no Rio Grande do Sul.

A procura pelas referências deu-se, inicialmente, por meio do Portal Periódicos Capes, elegendo-se sites de buscas, como Web of Science, Scopus, Science AAAS, EBSCO e Science Direct, com o intuito de verificar quais são as publicações internacionais que abordam o tema, observando como a temática está sendo discutida atualmente na comunidade acadêmica internacional, 
bem como as publicações e os autores mais citados que se encontram disponíveis para consulta e análise. Também foram consultados livros, revistas, sites e demais publicações relacionados ao tema. Assim foram selecionadas as palavras-chave de interesse: maket orientation AND agric*; market orientation AND wine; market orientation AND structure, conduct performance; structure, conduct performance AND wine; market orientation AND geographical indication, wine; structure, conduct performance AND geographical indication, wine.

A coleta de dados secundários foi realizada em sites do Instituto Brasileiro do Vinho (IBRAVIN), da Associação dos Produtores de Vinhos Finos do Vale dos Vinhedos (APROVALE) e da Empresa Brasileira de Pesquisa Agropecuária Uva e Vinho (EMBRAPA Uva e Vinho) e, também, mediante contatos com os pesquisadores Jaime Milan, Loiva Maria de Melo e Leocir Botega por telefone e e-mails. Neste estudo, o vinho fino é aquele elaborado exclusivamente de variedades Vitis vinifera, com cepas, geralmente, de origem europeia.

Por se tratar de um estudo qualitativo, optou-se pela seleção de categorias de análise determinadas a priori:

Categoria 1 - O fluxo turístico na região do Vale dos Vinhedos: justifica-se pelo fato de o aumento no fluxo de turista intensificar as vendas nas vinícolas, aumentar a divulgação da região em outras cidades, estados e países, bem como a renda da população e gerar desenvolvimento para a região;

Categoria 2 - O número de empresas que ingressou na Aprovale nos últimos anos: isso demonstra o diferencial competitivo do quanto a Indicação de Procedência Vale dos Vinhedos influencia um produto em termos de qualidade, valor agregado, reconhecimento da marca e também faturamento; e

Categoria 3 - O volume das exportações de vinho no Brasil: o estado do Rio Grande do Sul é responsável por $90 \%$ da produção nacional, possui informações de comercialização, cuja análise permite ter uma boa aproximação do desempenho econômico da agroindústria vinícola do Brasil. O volume das exportações mostra o interesse pelo vinho gaúcho em outros mercados. Nessa categoria, os vinhos foram classificados, segundo a Nomenclatura Comum de Mercadorias (NCM), disponível no site do Sistema de Análise das Informações de Comércio Exterior, via Internet (Alice-Web), da Secretaria de Comércio Exterior (SECEX) e do Ministério do Desenvolvimento, Indústria e Comércio Exterior (MDIC). Assim, a NCM 2204.2100 refere-se a "[...] outros vinhos, mostos de uvas, ferm. imped. álcool, recips <=2L [...]" e a NCM 2204.2900, a "[...] outros vinhos, mostos de uvas, ferm. imped. por adição alco". 
A análise feita é o resultado da triangulação entre o problema que impulsiona o estudo, os indicativos encontrados na teoria e os elementos identificados nas pesquisas já elaboradas, buscando-se, ainda, identificar lacunas a serem preenchidas em pesquisas futuras.

\section{A REGIÃO DO VALE DOS VINHEDOS E A INDICAÇÃO GEOGRÁFICA}

Conhecido pelos vales que compõem a sua paisagem, o "Vale dos Vinhedos" é uma pequena região que foi colonizada em meados de 1875 por imigrantes italianos vindos principalmente das regiões de Trento e Vêneto, Itália. Está localizado na macrorregião geográfica Sul do Brasil, na Encosta Superior do Nordeste do Rio Grande do Sul, conhecida como "Serra Gaúcha", ficando entre as cidades de Bento Gonçalves, Garibaldi e Monte Belo do Sul, totalizando 81 $\mathrm{km}^{2}$. O Distrito Vale dos Vinhedos foi criado em 17 de agosto de 1990, pertencendo ao município de Bento Gonçalves, com as seguintes linhas: Leopoldina, Graciema e Zamith (APROVALE, s.d.).

A região do Vale dos Vinhedos caracteriza-se por uma altitude média de 742 metros e por uma viticultura localizada, geralmente, no meio da encosta dos vales da Serra Gaúcha. A região possui clima do tipo temperado, com invernos rigorosos e períodos de sol durante o verão, tal como o encontrado em grande parte da viticultura europeia, conferindo à uva e ao vinho uma tipicidade regional. Os vinhedos não são irrigados, e a videira desenvolve-se por regime de chuvas (APROVALE, s.d.).

O Vale dos Vinhedos produz aproximadamente $90 \%$ da produção gaúcha de vinho e possui uma grande quantidade de vinícolas, destacando-se as 23 associadas à Aprovale. Na Aprovale, destacam-se também 43 empreendimentos não produtores de vinho, entre eles hotéis e pousadas, restaurantes, cafés, operadoras de turismo, ateliês de artesanato e antiguidades, queijaria e agroindústrias de geleias, doces e biscoitos (APROVALE, s.d.).

O Vale dos Vinhedos, em 22 de novembro de 2002, foi a primeira IG brasileira reconhecida pelo Instituto Nacional de Propriedade Industrial (INPI), onde foi assinado o Registro de Indicação Geográfica no IG 200002, que reconhece a denominação "Vale dos Vinhedos" na Serra Gaúcha/RS, na modalida- 
de de Indicação de Procedência para vinhos tintos, brancos e espumantes. Em 2007, foi reconhecida pela União Europeia, facilitando a exportação desses vinhos e espumantes nos países que integram a União Europeia.

Os produtos que recebem o selo de Controle Vale dos Vinhedos devem ser elaborados conforme o Regulamento da Indicação de Procedência do Vale dos Vinhedos, que incorpora doze inovações em relação à produção convencional de vinhos no Brasil. Tais inovações incluem aspectos da produção, controle e comercialização de vinhos de qualidade. São elas: a) Área geográfica de produção delimitada; b) Conjunto de cultivares autorizadas, todas da espécie Vitis vinifera L.; c) Limite de produtividade máxima por hectare; d) Origem da matéria-prima; e) Conjunto restritivo de produtos vinícolas autorizados; f) Elaboração, envelhecimento e engarrafamento dos produtos na área de produção delimitada; g) Controles de Produção Vitícola e Enológica; h) Padrões de identidade e qualidade química dos produtos; i) Padrões de identidade organoléptica dos produtos; j) Conselho regulador de autocontrole; k) Sinal distintivo para o consumidor por meio de normas específicas de rotulagem; e I) Respeito às Indicações Geográficas Reconhecidas.

Além da incorporação das inovações, os produtos são submetidos a controles realizados por um grupo de especialistas composto por técnicos da Embrapa Uva e Vinho de Bento Gonçalves e da Aprovale. Os selos têm número para controle e são aplicados como lacre, ligando a cápsula à garrafa, distinguindo-a das demais.

Em agosto de 2010, a Aprovale entrou no INPI com pedido de Denominação de Origem (DO), com o objetivo de valorizar os vinhos da região, consolidando-se como área diferenciada na elaboração de vinhos e espumantes de alto padrão. A DO orienta para a elaboração de produtos de alto valor agregado que possam extrair a máxima qualidade do terroir propiciado pela região, com competitividade internacional.

Desde 2002, após a IP, a região do Vale dos Vinhedos teve um grande impulso no turismo. E em 2016 chegou ao ápice, batendo recorde de público visitante. Foram 410.149 visitantes, um aumento de $3 \%$ em relação ao ano de 2015. Geralmente, os visitantes são casais e pequenos grupos familiares ou de amigos que visitam o vale com carro próprio ou alugado. Além disso, houve um aumento significativo de visitantes estrangeiros vindos de países como Alemanha, China, Rússia, EUA, França, Inglaterra, Argentina e Uruguai. Essa é uma 
região pioneira no enoturismo, o que justifica o grande fluxo de pessoas, apresentando o período de maior fluxo no inverno, entre os meses de junho e agosto (APROVALE, s.d.).

Na produção local, são 23 vinícolas associadas à Aprovale, as quais correspondem a $17 \%$ dos vinhos finos e a $12 \%$ dos espumantes nacionais, com uma média anual entre 10 a 12 milhões de garrafas. Além disso, há a produção de sucos e outros derivados de uvas. O perfil dessas vinícolas costuma ser variado, algumas são vinícolas familiares, com elaboração limitada e venda exclusiva em seu varejo, como também grandes empresas com reconhecimento internacional (APROVALE, s.d.).

Quanto à comercialização de vinhos e derivados, as vendas no mercado interno tiveram uma queda de mais de $18 \%$ em 2015. Já no mercado externo, tiveram uma significativa elevação em 2013. Após isso, obtiveram também uma queda de $84 \%$, conforme apresenta a Figura 2.

Figura 2 - Comercialização de vinhos finos no Rio Grande do Sul - Mercado interno e externo
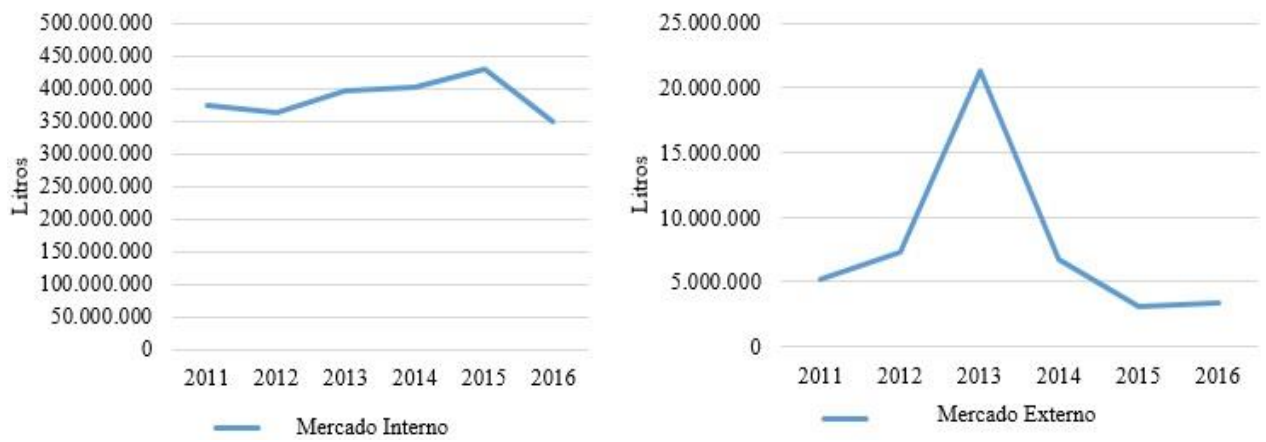

Fonte: Uvibra (Sem data de publicação. On-line [a]).

A queda tanto no mercado interno quanto no externo justifica-se pela atual crise econômica que o Brasil está passando e que afetou os estados da federação e diversos setores da economia - neste caso, a vitivinicultura. Além disso, a safra da uva, no ano de 2015 , sofreu intempéries climáticas, ocorrendo o aumento do preço do produto e a diminuição do consumo interno de vinho e de seus derivados.

Quanto às exportações brasileiras de vinho, houve um crescimento de $33 \%$ no primeiro semestre de 2016 . Em relação ao volume, as vendas cresce- 
ram $26 \%$ com a remessa de 835,5 mil litros. Além disso, houve um aumento no preço, passando de US\$2,51 para US\$2,65. Na Tabela 1, são apresentados os principais países que adquiriram vinho brasileiro em 2016.

Tabela 1 - Ranking dos países compradores do vinho brasileiro em 2016

\begin{tabular}{|c|c|c|c|c|}
\hline Posição & País & Volume & Valor US\$ & US\$/L \\
\hline 1 은 & Paraguai & 331.303 & $510.717,00$ & 1,54 \\
\hline 20 & EUA & 144.751 & $444.673,00$ & 3,07 \\
\hline 30 & Reino Unido & 83.306 & $335.416,00$ & 4,03 \\
\hline 40 & Colômbia & 111.590 & $278.976,00$ & 2,50 \\
\hline 50 & China & 19.062 & $89.235,00$ & 4,68 \\
\hline 60 & Finlândia & 15.139 & $76.951,00$ & 5,08 \\
\hline 70 & Alemanha & 13.355 & $65.688,00$ & 4,92 \\
\hline 80 & Canadá & 10.292 & $56.813,00$ & 5,52 \\
\hline 90 & Japão & 18.224 & $55.791,00$ & 3,06 \\
\hline 10 은 & Bolívia & 12.338 & $39.676,00$ & 3,22 \\
\hline
\end{tabular}

Fonte: Ibravin (2016).

Observa-se que um país da América Latina, nesse caso o Paraguai, foi o maior importador de vinho brasileiro em 2016, seguido pelos Estados Unidos, Reino Unido, Colômbia, China, Finlândia, Alemanha, Canadá, Japão e Bolívia. Segundo o presidente do Ibravin, as Olimpíadas foram fundamentais para a visibilidade dos produtos brasileiros pelos estrangeiros. Além disso, outros fatores foram fundamentais, como o ajuste na estratégia comercial com o mercado norte americano, a retomada de vendas para o Reino Unido e o amadurecimento nos mercados tradicionais, como é o caso do Paraguai, pelas vinícolas exportadoras (IBRAVIN, 2016). 


\section{ANÁLISE DOS RESULTADOS}

Ao analisar os resultados encontrados, percebe-se que a IG Vale dos Vinhedos, como instrumento de orientação para o mercado, tornou-se um diferencial para as vinícolas e outras organizações inseridas na Aprovale, demonstrando uma performance econômica significativa, contrária ao que se encontrava antes da IG.

Na estrutura do mercado vinícola do Vale dos Vinhedos, percebe-se uma performance econômica (SCHERER, 1996) que se caracteriza pelo número de vinícolas associadas, o qual duplicou nos últimos oito anos. Ou seja, o produtor está buscando qualidade e agregar valor aos seus produtos, o que culmina com a abertura de novos mercados. A Aprovale (s.d.) ressalta que a IG desencadeou uma série de impactos econômicos, como a valorização das terras das propriedades agrícolas entre 200 a 500\%, o incremento de área plantada com uvas viníferas e a melhoria no padrão tecnológico.

Uma situação que também serve para demonstrar a performance econômica (SCHERER, 1996) das organizações vinícolas a partir da IG é o fluxo turístico na região do Vale dos Vinhedos, que aumentou mais de 304\% desde 2001. A circulação de turistas na região fez crescer o faturamento das vinícolas que abrem as suas agroindústrias para visitação, degustação e apresentação dos seus produtos, gerando um resultado que se observa no aumento das vendas, mostrando, assim, o quanto as vinícolas estão orientadas para o mercado (PELHAM; WILSON, 1996; NARVER; SLATER, 1990).

No que tange à comercialização de vinhos finos no Brasil, percebe-se que as vendas, no mercado interno, estão caindo cada vez mais. No comércio de vinhos, em 2000, 46\% dos vinhos eram importados; em 2009, essa porcentagem subiu para $75,6 \%$. As razões que impulsionam esse cenário são: a retração do mercado consumidor europeu, que faz do Brasil um destino para produtores desovarem estoques; a entrada de vinhos ilegais no Brasil, oriundos principalmente da Argentina e do Chile (juntos representam 65\% dos vinhos comercializados no país), que entram sem pagar imposto de importação; e um movimento de antecipação de compras pelos importadores para evitarem gastos com a entrada em vigor, em janeiro de 2011, do novo selo fiscal de controle (UVIBRA, s.d. [b]).

O novo selo de controle fiscal, instituído a partir da Instrução Normativa RFB no 1.065 , em 19 de abril de 2010, objetiva promover ajustes nas regras 
relacionadas ao Registro Especial e ao Selo de Controle a que estão submetidos os produtores, os engarrafadores, as cooperativas, os estabelecimentos comerciais atacadistas e os importadores de vinhos. $O$ selo fiscal garante maior fiscalização sobre o contrabando, diminuindo a informalidade, além de servir para estimular a competitividade do vinho brasileiro no mercado interno e externo (BRASIL, 2010). Assim, esse selo cria expectativas para o setor de vinhos, principalmente quanto ao aspecto de aumento das vendas para o mercado interno, possibilitando, dessa forma, um aumento da performance econômica.

Vale lembrar, também, que o Brasil possui um mercado com potencial de crescimento, pois o consumo per capita é de dois litros ao ano, ocupando uma das últimas posições no mundo se comparado ao consumo em países como Chile e Argentina, cujo consumo individual é acima de 25 litros de vinho/ ano (UVIBRA, s.d. [b]).

Ao contrário das importações, o comércio de vinhos brasileiros para outros países vem crescendo ano após ano. Após 2004, o crescimento constante das exportações é resultado da criação da marca Wines from Brazil, em que 17 vinícolas brasileiras criaram um ambiente propício ao associativismo, sendo parceiras em um programa conjunto de exportação de vinhos finos, e, principalmente, do reconhecimento da IG Vale dos Vinhedos, em 2007, pela União Europeia.

O aumento das exportações de vinhos e as iniciativas promovidas pelas vinícolas brasileiras por meio de instrumentos de orientação para o mercado, como é o caso da IG Vale dos Vinhedos, promove, acima de tudo, a internacionalização do setor, apresentando um produto diferenciado com valor agregado em um mercado exigente e competitivo que é o do vinho fino. $O$ resultado dessa internacionalização e do aumento das exportações é uma performance econômica superior para a vinicultura gaúcha.

\section{ORIENTAÇÃO PARA O MERCADO, O SCP E A INDICAÇÃO GEOGRÁFICA VALE DOS VINHEDOS}

Com base na abordagem de orientação para o mercado, na exposição do paradigma SCP e nos conceitos de Indicação Geográfica foi possível explorar os elementos da estrutura, da conduta e da performance no comportamento 
de estruturação, organização e dinâmica de transformação do setor vinícola. Embora o paradigma SCP tenha sido desenvolvido em uma perspectiva de entendimento das condutas e do desempenho de empresas individuais, a discussão teórica, conduzida anteriormente, revela o espaço de possibilidades de se buscar e explorar os elementos do modelo SCP agora no contexto de empresas envolvidas em processos de estratégia e organização no agronegócio.

A Figura 3 apresenta uma estrutura analítica que mostra, paralelamente, os elementos do modelo SCP e como eles impactam ou determinam o comportamento e as possibilidades das empresas por meio da IG de procedência como instrumento de orientação para o mercado, como é o caso das vinícolas participantes da IG Vale dos Vinhedos.

Figura 3 - Estrutura Analítica Explorada

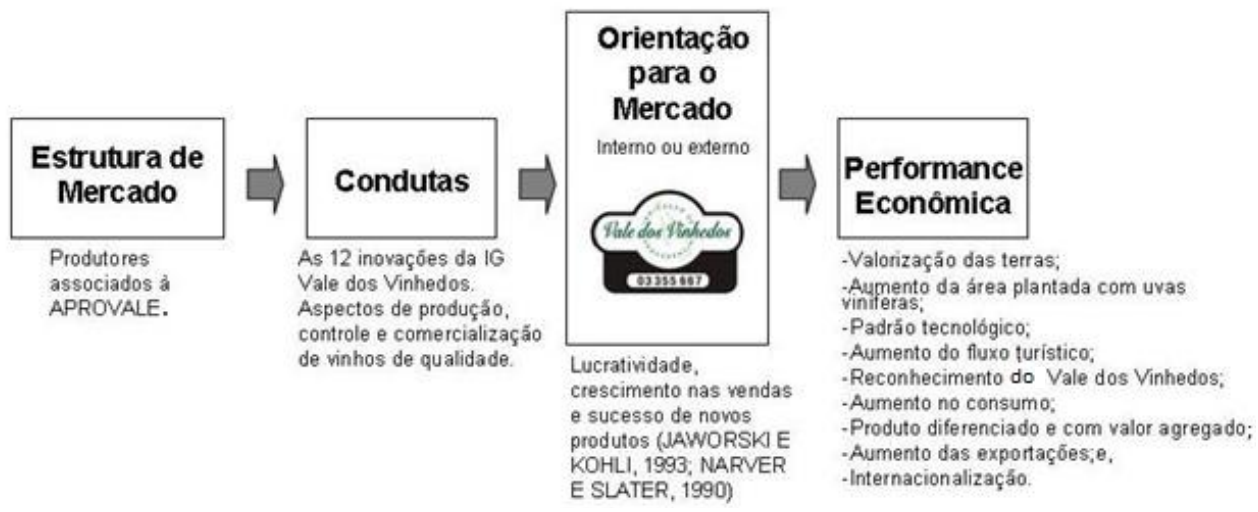

Fonte: Elaborada pelos autores.

Na Figura 3, observa-se a estrutura de mercado, formada principalmente pelos produtores de vinhos finos associados à Aprovale. As condutas das vinícolas são baseadas nas 12 inovações propostas para se obter a IG Vale dos Vinhedos, já que sem elas os vinhos não podem ser certificados. A orientação para o mercado, tanto interno como externo, é baseada nas variáveis de lucratividade, crescimento das vendas e sucesso de novos produtos.

Assim, a partir da IG Vale dos Vinhedos, pode-se entender que esse instrumento funciona como uma orientação para o mercado a partir do entendimento de que as vinícolas alcançam uma performance econômica por meio da valorização das terras; do aumento da área plantada com uvas viníferas; do padrão tecnológico; do aumento do fluxo turístico; do reconhecimento por meio 
da DO Vale dos Vinhedos; do aumento no consumo; do produto diferenciado e com valor agregado, bem como das exportações e da internacionalização.

\section{CONSIDERAÇÕES FINAIS}

A partir dos resultados, foi analisada a performance econômica por meio da IG como instrumento de orientação de mercado das vinícolas produtoras de vinhos finos no Vale dos Vinhedos. O estudo mostra que as organizações com IG Vale dos Vinhedos, como instrumento de orientação para o mercado, podem abrir seu acesso aos mercados de exportação, aumentar receitas de exportação e melhorar a vida de todos os agentes envolvidos no agronegócio do vinho fino. Assim, torna-se fundamental para qualquer indústria, seja do setor do agronegócio ou não, dispor de instrumentos que apresentem o grau de orientação para o mercado e comprovem que este realmente garante uma performance superior, como é o caso das IGs.

$\mathrm{O}$ aspecto do desenvolvimento da comunidade na região do Vale dos Vinhedos, por intermédio do movimento turístico, é outro fator que possibilita uma performance econômica e impulsiona a economia regional. Todos os associados da Aprovale, sejam vinícolas ou não, beneficiam-se da valorização da região, que Ihes proporciona resultados financeiros satisfatórios e desenvolvimento local.

Quanto ao comércio de vinhos finos no Brasil, percebe-se que o consumidor valoriza mais o produto importado. Nesse sentido, cabe aos produtores e órgãos de classe, juntamente com o poder público, promoverem iniciativas que incentivem o brasileiro a valorizar o que é da terra, já que o vinho nacional possui tecnologia e qualidade superior a outros vinhos e também valor agregado se comparado com outros produtos importados.

Como propostas para pesquisas futuras, sugere-se que os estudos abordem a orientação para o mercado em outros setores do agronegócio que possuam IG, para analisar a estrutura de mercado, as condutas e a performance econômica antes e depois de sua associação a ela. Outra sugestão de pesquisa é apurar os custos que têm de ser suportados na manutenção de uma IG para determinar a contribuição líquida da IG aos lucros, pois os custos, decorrentes de uma implantação de uma IG, como instrumento orientado para o mercado, podem ultrapassar os benefícios advindos de uma orientação para o mercado. 
É importante destacar que, no cenário vinícola gaúcho, caracterizado pela competitividade e pela busca incansável da conquista de novos mercados, torna-se necessário dispor de informações precisas sobre os clientes alvo, os concorrentes e os fornecedores. Conhecendo as preferências, as necessidades e as exigências do mercado consumidor, maiores são as oportunidades de fornecimento de um produto com valor superior, resultando na satisfação e no alcance da performance diferenciada.

Como limitação para este estudo, ressalta-se a dificuldade de mensuração e de obtenção de dados, o que permitiu apenas uma análise qualitativa da performance econômica antes e depois da inserção da IG Vale dos Vinhedos.

\section{REFERÊNCIAS BIBLIOGRÁFICAS}

ADDOR, F.; GRAZIOLI, A. Geographical indications beyond wines and spirits: a roadmap for a better protection for geographical indications in the WTO/TRIPPS agreements. The Journal of Intelectual Property, v. 5, n. 6, p. 865-897, nov. 2002.

ASSOCIAÇÃO DOS PRODUTORES DE VINHOS FINOS DO VALE DOS VINHEDOS APROVALE. O Vale. Sem data de publicação [on-line]. Disponível em: <http:// www.valedosvinhedos.com. br/vale/conteudo.php?view=67\&idpai=126\#null>. Acesso em: 24 fev. 2017.

BADCOCK, B. A.; CLEMENS, R. Geographical Indications and Property Rights: Protecting Value-Added Agricultural Products. MATRIC Briefing Paper 04-MBP 7, p. 1-51, may 2004.

BAIN, J. Industrial Organization. 2. ed. New York: Wiley, 1968.

BRASIL. Decreto $\mathrm{n}^{\circ}$ 1.355, de 30 de dezembro de 1994. Promulga a Ata Final que Incorpora os Resultados da Rodada Uruguai de Negociações Comerciais Multilaterais do GATT. Diário Oficial [da] República Federativa do Brasil. Brasília, DF, 31 de dezembro de 1994. Disponível em: <http://www.planalto.gov.br/ccivil_03/ decreto/antigos/d1355.htm>. Acesso em: 07 ago. 2010.

BRASIL. Lei $n^{\circ}$ 9.279, de 14 de maio de 1996. Regula direitos e obrigações relativos à propriedade industrial. Diário Oficial [da] República Federativa do Brasil. Brasília, DF, 15 de maio de 1996. Brasília. Disponível em: <http://www.planalto. gov.br/ccivil/LEIS/L9279.htm>. Acesso em: 07 ago. 2010. 
BRASIL. Receita Federal do Brasil. Instrução Normativa RFB no 1065, de 16 de agosto de 2010. Altera a Instrução Normativa RFB № 1.026, de 16 de abril de 2010, e a Instrução Normativa SRF № 504, de 3 de fevereiro de 2005, que dispõe sobre o registro especial a que estão sujeitos os produtores, engarrafadores, as cooperativas de produtores, os estabelecimentos comerciais atacadistas e importadores de bebidas alcoólicas e sobre o selo de controle a que estão sujeitos esses produtos, e dá outras providências. Diário Oficial [da] República Federativa do Brasil. Brasília, DF: 17 ago. 2010. Disponível em: <http://normas.receita. fazenda.gov.br/sijut2consulta/link.action?visao=anotado\&idAto=16032>. Acesso em: 14 fev. 2017.

CADILHON, J. J. et al. Market linkages: Characterizing business-to-business relationships in Vietnamese vegetable supply chains. Acta Horticulturae 809, p. 135-146, 2009.

DAY, G. S. The capabilities of market-driven organizations. Journal of Marketing, v. 58, n. 4, p. 37-52, oct. 1994.

DESHPANDÉ, R. et al. Corporate culture, customer orientation, and innovativeness in Japanese firms - a quadrad analysis. Journal of Marketing, v. 57, n. 1, p. 23-27, jan. 1993.

FERGUNSON, P. R.; FERGUNSON G. J. Industrial economics: issues and perspectives. London: MacMillan, 1994.

FLORES, M. A. D. Diagnóstico do enoturismo brasileiro: um mercado de oportunidades. Brasília: SEBRAE; Bento Gonçalves: IBRAVIN, 2012.

GRUNERT, K. G. et al. Market orientation of value chains: A conceptual framework based on four case studies from the food industry. European Journal of Marketing, v. 39 n. 5/6, p. 428 - 455, 2005.

GRUNERT, K. G. et al. Market orientation in the mental models of decision-makers: Two cross-border value chains. International Marketing Review, v. 27, n. 1, p. 7-27, 2010.

HAN, J. K.; KIM, N.; SRIVASTAVA, R. K. Market Orientation and Organizational Performance: Is Innovation a Missing Link? The Journal of Marketing, v. 62, n. 4, p. 30-45, out. 1998.

HARRE, H.; PIRSCHER, F. The food industry in the new EU member states: A comparative view on structure, conduct and performance. Outlook on Agriculture, v. 38, n. 1, p. 23-29, 2009. 
INSTITUTO BRASILEIRO DO VINHO - IBRAVIN. Exportações de vinhos brasileiros crescem 33\% em valor no semestre. Publicado em 29 ago. 2016 [on-line]. Disponível em: <http://www.ibravin.org.br/Noticia/exportacoes-de-vinhos-brasileiros-crescem-33-em-valor-no-semestre/170>. Acesso em: 14 fev. 2017.

INSTITUTO NACIONAL DE PROPRIEDADE INDUSTRIAL - INPI. Lista com as Indicações de Procedências Reconhecidas. Publicado em forma de PDF aos 28 de junho de 2017a [on-line]. Disponível em: <www.inpi.gov.br/.../copy2_of_LISTACOMASINDICAESDEPROCEDNCIACONCEDIDAS_RPI2425_27Jun17.pdf $>$. Acesso em: 24 jul. 2017.

INSTITUTO NACIONAL DE PROPRIEDADE INDUSTRIAL - INPI. Pedidos de indicação geográfica concedidos e em andamento. Última data de publicação em 22 agos. 2017b. Disponível em: <http://www.inpi.gov.br/menu-servicos/indicacao-geografica/pedidos-de-indicacao-geografica-no-brasil>. Acesso em: 14 set. 2017.

JAWORSKI, B. J.; KOHLI, A. K. Market orientation: antecedents and consequences. Journal of Marketing, v. 57, n. 3, p. 53-70, jul. 1993.

JOSLING, T. The war on Terroir: Geographical indications as a transatlantic trade conflict. Journal of Agricultural Economics, v. 57, n. 3, p. 337-363, sep. 2006.

KIRCA, A. H.; JAYACHANDRAN, S.; BEARDEN, W. O. Market Orientation: A Meta-Analytic Review and Assessment of Its Antecedents and Impact on Performance. Journal of Marketing, v. 69, n. 2, p. 24-41, apr. 2005.

KOHLI, A. K.; JAWORSKI, B. J. Market Orientation: The construct, research propositions, and managerial implications. Journal of Marketing, v. 54, n. 2, p. 1-18, apr. 1990.

LEAR, R. W. No easy road to market orientation. Harvard Business Review, v. 41, n. 5, p. 53-60, sep. 1963.

MASON, E. S. Price and production policies of large scale enterprises. American Economic Review, v. 29, n. 1, p. 61-74, 1939.

MCWILLIAMS, A.; SMART, D. Efficiency v. structure-conduct-performance for strategy research and practice. Journal of Management, v. 19, n. 1, p. 63-68, 1993.

MICHEELS, E. T.; GOW, H. R. The Impact of Alternative Market Orientation Strategies on Firm Performance: Customer versus Competitor Orientation. Agricul- 
tural \& Applied Economics Association's 2010 AAEA, CAES \& WAEA Joint Annual Meeting, Denver, Colorado, july 25-27, 2010.

MOORE, H. L.; HUSSEY, G. Economic implications of market orientation. Journal of Farm Economics, v. 47, n. 2, p. 421-427, may 1965.

MOSCHINI, G.; MENAPACE, L.; PICK, D. Geographical Indications and the provision of quality in agricultural markets. American Journal of Agricultural Economics, v. 90, n. 3, p. 794-812, aug. 2008.

NARVER, J. C.; SLATER, S. F. The effect of a market orientation on business profitability. Journal of Marketing, v. 54, n. 4, p. 20-35, oct. 1990.

NWOKAH, N. G. Strategic market orientation and business performance: The study of food and beverages organizations in Nigeria. European Journal of Marketing, v. 42, n. 3/4, p. 279-286, 2008.

O'BRIEN, E. V. Protection des indications géographiques aux États-Unis. Bulletin de L'OIV, v. 71, p.4 27-461, may/jun. 1998.

PELHAM, A. M.; WILSON, D. T. A Longitudinal Study of the Impact of Market Structure, Firm Structure, Strategy, and Market Orientation Culture on Dimensions of Small-Firm Performance. Journal of the Academy of Marketing Science, v. 24, 1996.

PELHAM, A. M.; WILSON, D. T. Estratégia competitiva: técnicas para análise de indústrias e da concorrência. 2. ed. Rio de Janeiro: Campus, 2005.

PORTER, M. E.; KRAMER, M. R. A vantagem competitiva da filantropia corporativa. In: RODRIGUES Y RODRIGUES, M. V. (Org.). Ética e responsabilidade social nas empresas. Tradução de Afonso Celso da Cunha Serra. Rio de Janeiro: Elsevier, 2005.

SCHERER, F. M. Industry structure, strategy and public policy. New York: Harper Collins, 1996.

SCHERER, F. M.; ROSS, D. Industrial market structure and economic performance. Boston: Houghton Mifflin Co., 1990.

SILVA, G. C. J. Propriedade intelectual e o comércio internacional: A Proteção da Propriedade Intelectual como um dos Determinantes-Chave para o Crescimento. 2010. 68 f. Tese (Doutorado em Economia) - Universidade Federal de Pernambuco, Recife, 2010. 
SIMPSON, P. et al. A Model of Value Creation: Supplier Behaviors and Their Impact on Reseller-Perceived Value. Industrial Marketing Management, v. 30, n. 2, p. 119-34, 2001.

SLATER, S. F.; NARVER, J. C. Does competitive environment moderate the market orientation-performance relationship. Journal of Marketing, v. 58, n. 1, p. 46-55, jan. 1994.

SLATER, S. F.; NARVER, J. C. Market orientation and the learning organization. Journal of Marketing, v. 59, n. 3, p. 63-74, jul. 1995.

SUBRAMANIAN, R.; KUMAR, K.; STRANDHOLM, K. The relationship between market orientation and performance under different environmental conditions: the moderating effect of the top management team's risk taking behavior. Academy of Strategic Management Journal, n. 8, jan. 2009.

TEIXEIRA, C. G. Proteção internacional de marcas. Revista Brasileira de Direito Internacional, v. 4, n. 4, 2006.

TREJO-PECH, C. O. et al. Appellation of Origin Status and Economic Development: A Case Study of the Mezcal Industry. International Food and Agribusiness Management Review, v. 13, n. 2, 2010.

TUNG, G. S.; LIN, C. Y.; WANG, C. Y. The market structure, conduct and performance paradigm re-applied to the international tourist hotel industry. African Journal of Business Management, v. 4, n. 6, p. 1116-1125, jun. 2010.

UNIÃO BRASILEIRA DE VITIVINICULTURA - UVIBRA. Comercialização de vinhos e derivados elaborados no Rio Grande do Sul: 2005 a 2010 - mercado interno e externo - em litros. Documento em PDF. Sem data de publicação [on-line] [b]. Disponível em: <http://www.uvibra.com.br/pdf/comercializacao2005a2010_dez. pdf>. Acesso em: 24 fev. 2017.

UNIÃO BRASILEIRA DE VITIVINICULTURA - UVIBRA. Comercialização de vinhos e derivados elaborados no Rio Grande do Sul: 2011 a 2016 - mercado interno e externo - em litros. Documento em PDF. Sem data de publicação [on-line] [a]. Disponível em: <http://www.uvibra.com.br/pdf/comercializacao2011a2016_dez. pdf>. Acesso em: 24 fev. 2017.

VAN DER WURFF, R. Structure, conduct, and performance of the agricultural trade journal market in The Netherlands. Journal of Media Economics, v. 16, n. 2, p. 121-138, 2003. 
VERHEES, F. J. H. M.; MEULENBERG, M. T. G. Market orientation, product innovation, and performance in small firms. Journal of Small Business Management, v. 42, n. 2, p. 134-154, 2004.

VIAENE, J.; GELLYNCK, X. Structure, conduct and performance of the European food sector. European Review of Agricultural Economics, v. 22, n. 3, p. 282-295, 1995.

WANG, C. L. et al. Knowledge management orientation, market orientation, and firm performance: an integration and empirical examination. Journal of Strategic Marketing, v. 17, n. 2, p. 99-122, 2009.

WILKINSON, J. Transformações e perspectivas dos agronegócios brasileiros. Revista Brasileira de Zootecnia, v. 39, 2010. 